\title{
SERVIÇO PÚBLICO DE LIMPEZA EM CRISE: POLÍTICA NACIONAL DE RESÍDUOS SÓLIDOS E ASPECTOS DA ECONOMIA CIRCULAR PARA A LOGÍSTICA REVERSA
}

\author{
Késia Rocha Narciso* \\ Valter Foletto Santin ${ }^{* *}$ \\ Ilton Garcia da Costa ${ }^{* * *}$
}

\begin{abstract}
RESUMO
Os serviços públicos de limpeza já passavam por uma crise, agravada pelo COVID-19, há a questão orçamentária e o aumento dos gastos necessários para medidas de proteção. $\mathrm{O}$ objetivo do artigo é demonstrar as perspectivas da economia circular para auxiliar na logística reversa ante a crise nos serviços públicos de limpeza urbana. Utilizou-se a técnica de pesquisa bibliográfica e o método dedutivo. Os principais resultados demonstram a necessidade de adoção de novas perspectivas para geração de renda e logística reversa; principais conclusões destacam a relevância da economia circular no Brasil, para alcance do ciclo reverso e dos objetivos da legislação.
\end{abstract}

Palavras-chave: Serviços Públicos; Limpeza Urbana; PNRS; Economia Circular; Logística Reversa.

\section{PUBLIC CLEANING SERVICE IN CRISIS: NATIONAL SOLID WASTE POLICY AND CIRCULAR ECONOMY ASPECTS FOR REVERSE LOGISTICS}


article is to demonstrate the prospects of the circular economy to assist in reverse logistics before the crisis in public cleaning services. The bibliographical research technique and the deductive method were used. The main results demonstrate the need to adopt new perspectives for income generation and reverse logistics; main conclusions highlight the relevance of the circular economy in Brazil, to achieve the reverse cycle and the objectives of the legislation.

Keywords: Public Services; Urban Cleaning; NSWP; Circular Economy; Reverse Logistics.

\section{INTRODUÇÃO}

Os serviços públicos ofertados à população são essenciais, e sua prestação, garantida pela Constituição, impõe ao estado a garantia de instrumentos para efetivação desses direitos fundamentais.

Dentre eles, o serviço público de limpeza urbana, enquadra-se também nos serviços de saneamento básico, detendo ainda utilidade pública e garantia de vida digna.

Tem-se o problema orçamentário que o setor já vinha padecendo e que se agravou com o advento da pandemia de coronavírus, demandando por maiores gastos para evitar contaminação.

A Política Nacional de Resíduos Sólidos (PNRS) constitui importante instrumento legal para a discussão, dispondo sobre o gerenciamento dos resíduos e sobre os sistemas de logística reversa.

As questões referentes à situação do serviço público de limpeza no Brasil e as implicações resultantes de uma crise que já se vivenciava há tempos, demandam por ações em diversos níveis, para sua mitigação.

É de suma importância a discussão sobre os instrumentos legais da Política Nacional de Resíduos Sólidos para a logística reversa, enquanto essencial para efetivação da economia circular no Brasil, para otimizar os serviços de limpeza urbana.

Faz-se necessário registrar os aspectos da economia circular e a necessidade de adoção de tais perspectivas para auxiliar a logística reversa e acelerar a transição para a circularidade no país.

O objetivo da pesquisa é demonstrar as perspectivas da economia circular para auxiliar na logística reversa ante a crise nos serviços públicos de limpeza urbana, considerando os objetivos propostos pela Política Nacional de Resíduos Sólidos. 
A metodologia adotada foi a técnica de pesquisa bibliográfica, materiais tais como livros, artigos científicos, trabalhos acadêmicos, disponíveis em meio físico ou on-line e o método dedutivo de abordagem para sua realização.

\title{
2 SERVIÇO PÚBLICO DE LIMPEZA EM CRISE
}

A preocupação com a garantia de direitos tem relação com a atuação e proteção estatal, visando os direitos sociais, previstos pela Constituição da República, e que compõem os direitos humanos, dentre eles o serviço público.

Nesse sentido, discute Santin:

\begin{abstract}
O direito ao serviço público pode ser considerado mais um direito humano ou direito fundamental, para a convivência social, efetivação dos direitos sociais, busca da igualdade material e melhoria da qualidade de vida da população, como um direito a um padrão de vida mínimo, o chamado mínimo existencial, para bem-estar do ser humano e sua família. A colocação do serviço público como direito humano ou direito fundamental é um mecanismo de ação afirmativa, de prestígio e destaque dessa atividade ou função pública, um fator importante para a melhoria da prestação de serviço público ao povo, com inegável capacidade de transformação social, redução das desigualdades, melhor atendimento pelos órgãos públicos e instrumento importante para a efetivação dos direitos sociais e do mínimo existencial (2019, p. 147).
\end{abstract}

A prestação de alguns serviços é essencial para garantia de direitos fundamentais, como também, o seu bom funcionamento auxilia a manutenção de outros direitos, para tanto, o poder público deve exercer suas funções observando e executando um planejamento tanto orçamentário quanto assecuratório, "Cumpre ressaltar que condição social e desenvolvimento humano são alterados pelo desenvolvimento científico e tecnológico, que influencia reciprocamente o desenvolvimento" (PHILIPPI, 2017, p. V).

Assim, é preciso salientar que enquanto fundamentalidade formal, tendo em vista a constitucionalização dos direitos, normas de direito fundamental possuem hierarquia superior as demais normas do ordenamento jurídico, e sujeitas aos limites formais e materiais quanto a revisão e emenda constitucional e que além da aplicabilidade imediata, vinculam os poderes públicos (SARLET, 2005, p. 86-87), enquanto a fundamentalidade material está ligada a tais direitos e o núcleo valorativo, em especial a dignidade humana, conforme prevê a Constituição da República (BRASIL, 1988). 
Considerando o exposto, "O mínimo existencial, como representação dos direitos sociais, necessita de atendimento pelo Estado, como prestação positiva, em serviços públicos correspondentes a políticas públicas e busca da dignidade da pessoa humana" (LOUREIRO, SANTIN, LIMA, 2020, p. 21).

A Administração Pública possui diversas funções principais, uma delas refere-se à limpeza urbana que enquadra-se na esfera da engenharia sanitária e enquanto serviço público, conforme disposição constitucional no artigo 175, deve o poder público prestá-la (BRASIL, 1988).

Considerando a importância dos dados para auxiliar o poder público na tomada de decisões:

\begin{abstract}
Em relação a limpeza urbana e ao manejo de resíduos sólidos, drenagem e manejo das águas pluviais urbanas a captação de dados é mais difícil, visto que a pesquisa pode ter muitos objetos com resultados diferentes. Entretanto, chama a atenção os dados sobre a destinação do lixo produzido nos municípios brasileiros (COSTA, PIEROBON, SOARES, 2018, p. 340).
\end{abstract}

Geralmente o orçamento para este serviço é reduzido, entretanto, o seu bom funcionamento é essencial para alcançar objetivos relacionados a programas de saneamento, tendo em vista que o lixo pode: trazer problemas ambientais, por meio de agentes físicos, químicos e biológicos, causando assoreamento/ deslizamentos (físicos), poluição pela queima, contaminação de lençóis freáticos (químicos), e a proliferação de doenças pela propagação de transmissores (biológicos) (FERREIRA, JOCA, BROETTO, 2019, p. 4-5).

Diante disso, considerando o planejamento e o orçamento, e ainda, diante de situação pandêmica, conforme explicam Loureiro, Santin e Lima:

A atuação financeira é característica inerente ao Estado no regime democrático de Direito, devendo suas ações ter por pressuposto o planejamento e disposições legais específicas sobre as diretrizes para elaboração e concretização de políticas públicas. (...)

Para implementação das políticas públicas, devem os gestores se submeter aos regramentos sobre orçamento público, o qual se sujeita ao regime do princípio da legalidade e, como regra, suas normas devem ser respeitadas rigidamente, de tal forma que a flexibilidade é medida excepcional. Importa com isso que o remanejamento orçamentário entre elementos de despesas não é ordinariamente admitido.

(...)

Sendo assim, em face de uma pandemia, pelas características intrínsecas dos direitos fundamentais sociais essenciais, conclui-se que, como regra, há impossibilidade de remanejamento das verbas orçamentárias alocadas em rubrica destinada a uma 
política pública prestacional do mínimo vital para a realização de ações públicas diversas do cumprimento da prestação estatal (2020, p. 30; 36-37).

O setor já estava em crise pela falta de pagamento pelas prefeituras, e com a pandemia de covid-19 está em crise. No ano de 2019 as contas a receber de 6,2 bilhões, chegaram a 18 bilhões, enquanto o faturamento do setor é de 28 bilhões, como também, a inadimplência que era de 15\% a 18\% ao ano, em 2016 chegou em 40\% e com a pandemia, em 2020 pode chegar a 50\%, e os gastos aumentaram em 10\% para adoção de medidas em razão do covid-19 (AGÊNCIA, 2020).

Ao analisar o Índice de Sustentabilidade de Limpeza Urbana (ISLU), tem-se que:

\begin{abstract}
Por conta da revisão da metodologia do ISLU exigida pelo novo marco legal do saneamento, decorrente do rompimento com o modelo de sustentabilidade econômico-financeira dos serviços públicos de manejo de RSU dependente do orçamento, observa-se (...) uma queda acentuada na pontuação de todas as regiões do País, evidenciando que boa parte dos seus municípios, embora autorizados pela PNRS, não praticavam a cobrança para a remuneração dos serviços, agora de caráter obrigatório.

Em razão do significativo número de municípios que já contam a cobrança, a Região Sul do País sofreu uma queda menor que as outras regiões, remanescendo assim (...) a melhor pontuação do ISLU 2020. (ÍNDICE, 2020, p. 17)
\end{abstract}

A Lei 11.445 (BRASIL, 2007) estabelece as diretrizes nacionais para o saneamento básico, o Artigo $2^{\circ}$, III - dispõe sobre a “(...) limpeza urbana e manejo dos resíduos sólidos realizados de forma adequada à saúde pública, à conservação dos recursos naturais e à proteção do meio ambiente".

Então, como ficaria a questão da interrupção do serviço diante da inadimplência? A prestação dos serviços de limpeza urbana é essencial para a proteção do meio ambiente e da saúde humana, e não pode ser interrompida, mesmo durante processos epidêmicos:

(...) o comprometimento estatal quanto aos serviços públicos tradicionais, por se tratar de atividades de interesse público e de necessidades básicas, deixa de ser executivo e passa a ser institucional e consiste no dever de garantir que as tarefas em causa sejam efetivamente exercidas (OLIVEIRA, 2016, p. 169).

$\mathrm{O}$ artigo $3^{\circ}$, inciso I, alínea “c”, define limpeza urbana e manejo de resíduos sólidos como:

(...) constituídos pelas atividades e pela disponibilização e manutenção de infraestruturas e instalações operacionais de coleta, varrição manual e mecanizada, 
asseio e conservação urbana, transporte, transbordo, tratamento e destinação final ambientalmente adequada dos resíduos sólidos domiciliares e dos resíduos de limpeza urbana (BRASIL, 2007).

O novo marco do saneamento (tem o intuito de viabilizar a universalização dos serviços até 31/12/2033) - A Lei 14.206 de 2020 (BRASIL) incluiu o Art. $3^{\circ}$-C dispõe que:

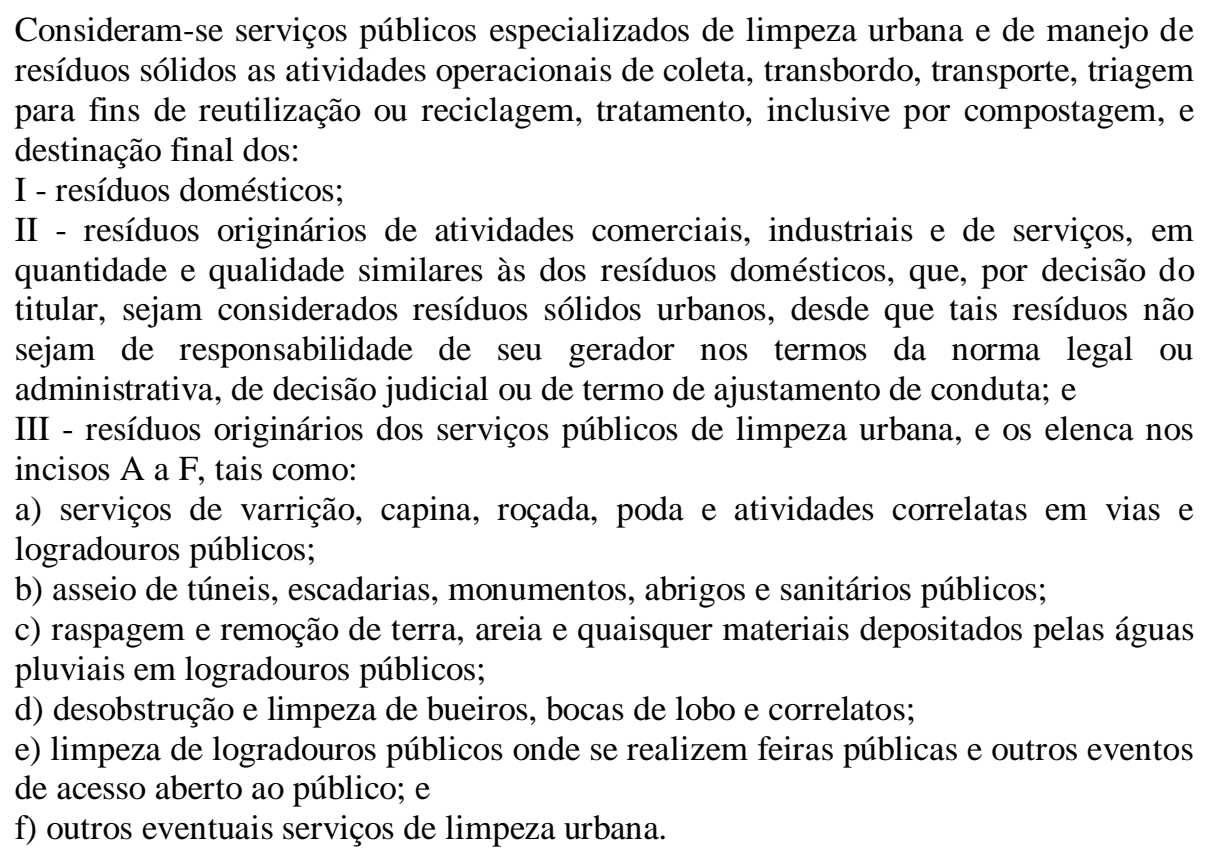

E no artigo $7^{\circ}$ (BRASIL, 2007) e incisos, dispõe sobre o conjunto de atividades relacionadas na alínea c do artigo $3^{\circ}$ da lei, que compõe este serviço, dentre os quais:

\begin{abstract}
(...) de coleta, de transbordo e de transporte dos resíduos (...) de triagem, para fins de reutilização ou reciclagem, de tratamento, inclusive por compostagem, e de destinação final dos resíduos (...) de varrição de logradouros públicos, de limpeza de dispositivos de drenagem de águas pluviais, de limpeza de córregos e outros serviços, tais como poda, capina, raspagem e roçada, e de outros eventuais serviços de limpeza urbana, bem como de coleta, de acondicionamento e de destinação final ambientalmente adequada dos resíduos sólidos provenientes dessas atividades.
\end{abstract}

Conforme prevê a Constituição da República (BRASIL, 1988), nos incisos I e V do artigo 30, cabe ao município legislar sobre assuntos de interesse local, como também está previsto no artigo $8^{\circ}$ da lei 11.445 (BRASIL, 2007), no caso, sobre o gerenciamento dos serviços de limpeza urbana, em regiões metropolitanas pode ocorrer intervenção do estado, como também municípios interessados podem por associação realizar consórcios para o gerenciamento de limpeza urbana e dos resíduos. 


\title{
3 POLÍTICA NACIONAL DE RESÍDUOS SÓLIDOS E LOGÍSTICA REVERSA
}

A urgência para lidar com o contexto de crise ecológica e a problemática dos resíduos, que tem elevado os riscos de catástrofes, poluição e provocado o surgimento de doenças, remete ao Estado o aprimoramento de alternativas para sua mitigação, Costa e Assahara destacam que:

\begin{abstract}
A sadia qualidade de vida apenas é alcançada por meio do equilíbrio ambiental. O status de sadio não implica em apenas ausência de agentes patogênicos, mas sim do equilíbrio dos fatores ambientais. As condições para promoção da saúde emergem como consequência do equilíbrio dinâmico entre a intervenção humana e o meio ambiente, sempre por meio de uma perspectiva axiológica de preservação ambiental (COSTA, ASSAHARA, 2020, p. 30).
\end{abstract}

Em se tratando da preocupação ecológica diante da crise evidenciada pela produção de lixo e resíduos e a necessidade de sua mitigação, com enfoque na Política Nacional de Resíduos Sólidos (BRASIL, 2010) e na logística reversa, há que se entender que resíduos sólidos urbanos, são os resíduos domiciliares (resíduos originários de atividades domésticas em residências urbanas) e os resíduos de limpeza urbana (resíduos originários da varrição, limpeza de logradouros e vias públicas e outros serviços de limpeza urbana.), porém, existem outros tipos de resíduos.

A Lei n 12.305 de 2 de Agosto de 2010 instituiu a Política Nacional de Resíduos Sólidos e demais providências, constituindo principal instrumento normativo para regulação da gestão integrada e gerenciamento de resíduos sólidos, e dentre os seus principais instrumentos tem-se: educação ambiental, os acordos setoriais, os estudos de regionalização, os planos municipais de gestão integrada de resíduos sólidos, como também planos intermunicipais de resíduos sólidos, os planos estaduais de resíduos sólidos e ainda o sistema nacional de informações sobre a gestão dos resíduos, como também, a coleta seletiva e os sistemas de logística reversa (inclusive por instrumentos econômicos, conforme artigo $8^{\circ}$, inciso III e 42 da PNRS) (BRASIL, 2010).

A definição legal para logística reversa encontra-se no artigo $3^{\circ}$ da PNRS que a dispõe como instrumento para desenvolvimento econômico e social que demandam por ações, processos e caminhos que viabilizem a coleta e devolução de resíduos sólidos ao setor 
empresarial para destinação adequada ambientalmente ou reinserção em seu ciclo ou outros ciclos por meio do reaproveitamento (BRASIL, 2010).

No art. $3^{\circ}$ para os efeitos da Lei, define-se:

\begin{abstract}
XII - logística reversa: instrumento de desenvolvimento econômico e social caracterizado por um conjunto de ações, procedimentos e meios destinados a viabilizar a coleta e a restituição dos resíduos sólidos ao setor empresarial, para reaproveitamento, em seu ciclo ou em outros ciclos produtivos, ou outra destinação final ambientalmente adequada;

(...)

XIX - serviço público de limpeza urbana e de manejo de resíduos sólidos: conjunto de atividades previstas no art. $7^{\circ}$ da Lei $\mathrm{n}^{\circ} 11.445$, de 2007.
\end{abstract}

Considerando o Panorama dos Resíduos Sólidos no Brasil, segundo a Associação Brasileira de Empresas de Limpeza Pública e Resíduos Especiais, "o volume coletado cresceu mais que a geração, atingindo 199.311 toneladas por dia. Houve expansão em todas as regiões do Brasil, com exceção do Nordeste (a única em que a população encolheu entre 2017 e 2018 , segundo as estimativas do IBGE)" (2019, p. 12).

Dentre as preocupações com a proteção e equilíbrio ambiental e a saúde pública, previstas na PNRS, especificamente nos objetivos instituídos no artigo $7^{\circ}$, destacam-se em seus incisos a necessidade de: a) não geração, redução, reutilização, reciclagem e tratamento dos resíduos sólidos, inclusive disposição final ambientalmente adequada dos rejeitos; b) estimular a adoção de padrões sustentáveis de produção e consumo de bens e serviços; c) adotar, desenvolver e aprimorar tecnologias limpas para minimização de impactos ambientais; d) reduzir o volume e periculosidade dos resíduos perigosos; e) incentivar a indústria da reciclagem, visando o fomento do uso de matérias-primas e insumos derivados de materiais recicláveis e reciclados; f) gestão integrada de resíduos sólidos; g) diálogo entre as diferentes esferas do poder público, integradas com o setor empresarial, para cooperação técnica e financeira na gestão integrada de resíduos sólidos; h) capacitação técnica continuada na área de resíduos sólidos (BRASIL, 2010), que se fundem aos princípios de economia circular.

A lei prevê ainda sobre a responsabilidade compartilhada pelo ciclo de vida do produto, e, consequentemente, sobre a logística reversa, dispondo em seu artigo $3^{\circ}$, inciso XVII; artigo 30; artigo 31, incisos III e IV sobre a abrangência da responsabilidade quanto aos importadores, fabricantes, distribuidores e comerciantes, como também os consumidores, os titulares dos serviços públicos de limpeza urbana e também os de manejo de resíduos sólidos, 
impondo obrigações para estruturação e implementação dos sistemas de logística reversa pelos atores vinculados (BRASIL, 2010).

Diversos outros dispositivos são essenciais para, por meio da responsabilidade compartilhada, proporcionar o avanço da matéria, as principais diretrizes quanto ao retorno de embalagens pelos sistemas de logística e as obrigações para estruturação e implementação encontram-se no artigo 33 da lei e seus parágrafos, podendo-se destacar os parágrafos $\S 2^{\circ}$, $\S 3^{\circ}, \S 4^{\circ}, \S 7^{\circ}$ e $\S 8^{\circ}$, que tratam da viabilidade técnica e econômica da logística reversa quanto à definição de produtos e embalagens e seu grau e extensão e impacto; responsabilidade compartilhada dos atores para implementá-la e operacionalizá-la; o dever do consumidor de devolução de produtos ou embalagens após o uso conforme especificações da lei; ações do poder público frente aos titulares de serviço público e responsabilidade, e, ainda, (excetuandose os consumidores) manutenção das informações atualizadas sobre as ações de responsabilidade de todos os participantes dos sistemas de logística reversa (BRASIL, 2010); o decreto $\mathrm{n}^{\circ} 10.240$ de 2020 normatiza quanto à obrigatoriedade de implementação do sistema de logística reversa de produtos eletroeletrônicos que sejam de uso doméstico e todos os componentes (BRASIL, 2020).

E o artigo Art. 36. dispõe que: "No âmbito da responsabilidade compartilhada pelo ciclo de vida dos produtos, cabe ao titular dos serviços públicos de limpeza urbana e de manejo de resíduos sólidos, observado, se houver, o plano municipal de gestão integrada de resíduos sólidos” (BRASIL, 2010).

Segundo a Abrelpe de 2018/2019 (p. 16), "Das 72,7 milhões de toneladas coletadas no Brasil em 2018, 59,5\% tiveram disposição final adequada e foram encaminhadas para aterros sanitários - expandindo 2,4\% em relação ao valor total do ano anterior"; há também:

(...) unidades inadequadas como lixões e aterros controlados ainda têm participação significativa ( $23 \%$ e $17,5 \%$, respectivamente). Estão presentes em todas as regiões e recebem mais de 80 mil toneladas de resíduos por dia, com elevado potencial de poluição ambiental e impactos negativos à saúde (ABRELPE, 2019, p. 16).

O novo relatório destaca que "Entre 2010 e 2019, a geração de RSU no Brasil registrou considerável incremento, passando de 67 milhões para 79 milhões de tonelada por ano. Por sua vez, a geração per capita aumentou de $348 \mathrm{~kg} /$ ano1 para $379 \mathrm{~kg} / \mathrm{ano"}$ (ABRELPE, 2020, p. 14). 
Tem-se os instrumentos para implementação e operacionalização dos sistemas de Logística Reversa decorrentes do decreto regulamentador da PNRS n ${ }^{\circ} 7.404 / 2010$, previstos no art. 15, são: "I - acordos setoriais; II - regulamentos expedidos pelo Poder Público; ou III termos de compromisso" (BRASIL, 2010).

A título exemplificativo visualiza-se que:

No âmbito do Acordo Setorial para Embalagens em Geral foi estabelecida uma articulação de empresas e de organizações da iniciativa privada visando unir forças e expertises em torno de um sistema de logística reversa viável, conforme diretrizes do edital do governo para apresentação de propostas. Aprovado pelo Ministério do Meio Ambiente após consulta pública, o compromisso empresarial da Coalizão Embalagens consiste principalmente no apoio estruturante às cooperativas de catadores de materiais recicláveis, ampliação do número de Pontos de Entrega Voluntária (PEV) para recebimento de resíduos e conscientização dos consumidores (CEMPRE, 2019, p. 6).

Para estabelecer o sistema de logística reversa o regulamento expedido pelo Poder Público é inserido e decretado pelo Poder Executivo, realizando-se consulta pública prévia; já os Acordos Setoriais, por meio contratual possibilitam o acordo entre o Poder Público e demais empresas (fabricantes, importadores, distribuidores ou comerciantes), como também esses atores poderão firmar Termos de Compromisso, na falta de acordos setoriais ou regulamento, ou ainda, por maior exigência (BRASIL, 2010).

Considerando que tais instrumentos dependem da legislação e do governo para sua materialização, como também existem necessidades regionalizadas, há uma dificuldade na implementação da logística reversa, que abrange ainda questões de custos, fiscais, tributárias e avaliativas para reinserção no ciclo reverso, portanto, o Brasil precisa adotar os instrumentos da Economia Circular para a tomada de medidas adequadas de estruturação, e alguns facilitadores são: educação, políticas públicas, infraestrutura (ex. logística reversa), tecnologias e inovação (LAURINDO; MICHELLY, 2016).

A PNRS instituiu instrumentos para implementar o princípio da responsabilidade compartilhada pelo ciclo de vida dos produtos, tem-se a logística reversa, que propõe a viabilização do reaproveitamento dos resíduos sólidos no processo produtivo, diminuindo o envio de materiais para a disposição no solo. Uma das prioridades na gestão e no gerenciamento dos resíduos sólidos, é a reciclagem - que é um processo de transformação de resíduos que envolve a alteração de propriedades físicas, físico-químicas ou biológicas 
originando novos insumos ou novos produtos, e os pilares da economia circular podem alavancar de maneira mais sustentável o setor.

\section{ASPECTOS DA ECONOMIA CIRCULAR PARA O CICLO REVERSO}

O papel estatal é ponte para que os princípios de economia circular possam alcançar concretização prática, como também, "o debate ambiental não pode fugir ao enfrentamento de tematizar qual é o modelo de Estado mais compatível para levar adiante a conjugação entre desenvolvimento e sustentabilidade” (BANNWART, SOUZA, 2013).

Antes de se falar na transição para uma economia circular, destaca-se a Economia Solidária, que no Brasil surgiu por volta de 1980, por conta do aumento do desemprego decorrente da crise inflacionária e cambial, e que promoveram diversos programas governamentais para auxiliar perspectivas econômicas e sociais para os trabalhadores, gerar renda e instituir políticas públicas (TRANNIN, COSTA, PINTO, 2015, p. 125-126).

Para implementação da circularidade, tem-se os princípios de Economia Circular em três perspectivas considerando a estrutura "ReSOLVE" (Regenerar, Compartilhar, Otimizar, Loop, Virtualizar e Troca), para: regenerar os sistemas vivos; manter produtos e materiais em múltiplos usos em seu mais alto valor; e estimular a geração de valor econômico retirando resíduos e poluição desde o início da cadeia (FOUNDATION, 2015).

Princípio 1: preservação e aprimoramento do capital natural por meio de controle de estoque e equilíbrio de fluxos dos recursos renováveis (para regenerar, virtualizar e trocar);

Princípio 2: otimização do rendimento de recursos para circularidade dos produtos, componentes e ainda materiais para uso no maior grau de utilização em todo o tempo, nos ciclos técnicos e biológicos (para regenerar, compartilhar, otimizar e promover a criação de circuitos);

Princípio 3: estimulação da efetividade sistemática mostrando e eliminando as externalidades negativas desde o início, considerando todos os elementos da estrutura "ReSOLVE".

Os princípios de Economia Circular visam desde a fase inicial: estimular a geração de valor econômico com o intuito de eliminar resíduos e poluição, manter os materiais em múltiplos usos em seu mais alto valor, e, regenerar os sistemas vivos, considerando os ciclos biológicos e técnicos. 
A PNRS estabeleceu a gestão integrada dos resíduos sólidos e em conjunto com os princípios e objetivos pautados na proteção e equilíbrio ambiental impôs aos diversos atores a adoção de medidas para sistematizar a logística reversa no intuito de promover o desenvolvimento sustentável, em observância a redução, reutilização e destinação adequada de resíduos sólidos, e se alinha aos princípios de economia circular que têm por escopo retirar os resíduos e poluição desde o início da cadeia produtiva, como também, gerar amplo aproveitamento dos materiais em seu mais alto nível de utilização sem insulto a natureza, e a logística reversa constitui importante instrumento para essa transição (BRASIL, 2010; FOUNDATION, 2017).

Porém, conforme já explanado, a modificação dos atuais cenários econômicos e ecológicos dependem de ajustes nas interpretações jurídicas, para que as leis e os princípios da economia circular estejam alinhados e efetivamente inseridos e a legislação possa ajudar a construir novas agendas e ações para que, em espiral, utilize-se um método baseado na ética, na ciência e pesquisa específica por meio de tecnologia e inovação, pois, observa e integra extensivamente as questões ambientais e econômicas, e utiliza a logística reversa como uma ferramenta inicial relevante para a implementação, até que a meta da economia circular seja alcançada.

Os estudos de Lewandowski (2016) contribuem para um amplo saber da economia circular, destacando o entendimento para que o equilíbrio ecológico não seja confundido com a sustentabilidade ecológica, aponta que esta última usa a economia circular como lucro sem desperdiçar materiais biológicos e tecnológicos para a transição para um modelo de negócios circular.

Neste sentido, considerando a prática, a Confederação Nacional da Indústria (CNI, 2018) apresenta uma característica importante da economia circular, ou seja, integrar os participantes dentro e entre os ciclos biológico e técnico, agregando valor às duas cadeias e à estrutura de logística reversa delas, pois, ao serem compartilhadas entre seus agregados, fortalece e reduz custos, já que, poucas novas empresas de reciclagem oferecem oportunidades em comparação com alternativas individuais.

No entanto, essa transição não acontece sozinha, a inter-relação dos participantes é a base. Do ponto de vista ecossistêmico, Parida e seus colaboradores (2019) propõem considerar a economia circular em duas etapas. Primeiro: avaliar a preparação da situação do ecossistema, segundo: transformar o ecossistema, e haverá mecanismos de implementação 
únicos e complementares em cada estágio, de modo que todas as partes interessadas, incluindo clientes, assumam novos papéis e responsabilidades, e a empresa precisa revisar como criar, entregar e adquirir valor.

Por diversos fatores, a logística reversa enfrenta dificuldades para implementar os princípios da economia circular, entre eles, a legislação é um entrave para estimular o progresso do setor industrial.

É preciso promover o debate entre os setores técnicos, unidades de compostagem e reciclagem, dilatar o sistema de coleta, inclusive encontrar soluções inteligentes de limpeza urbana, aliando tecnologia e inovação, reduzindo custos e promovendo o emprego.

Dessa forma, uma análise mais ampla, ecossistêmica, ajuda a entender como integrar serviços para garantir benefícios sustentáveis, modificando os modelos de negócios para integrar a economia circular e atrair seus parceiros do ecossistema (PARIDA et al., 2019).

Ao agregar os participantes de toda a cadeia produtiva, a logística reversa auxilia e é fundamental para a inserção dos princípios da economia circular, sendo possível integrar tecnologias e inovações ecológicas, socialmente sustentáveis, por meio do investimento em tecnologia e conhecimento técnico para superar seus obstáculos, promover ações integrais e de fortalecimento das parcerias entre os participantes, para que a logística reversa impulsione a transição do país para uma economia circular. Assim, ao se considerar que é preciso investir em alternativas diante do modelo atual, Costa e Cirelli apontam que a:

(...) crise vivenciada no setor que lida com o gerenciamento dos resíduos sólidos, considerada como consequência lógica dessa ótica de mercado, baseada no consumismo e desperdício, conceitos anteriormente comentados. Para se alcançar uma efetiva mudança, exigir-se-ia uma mudança radical do paradigma de produção prevalecente na cultura fundamentada na crescente acumulação de riquezas e efemeridade daquilo que se obtém; entretanto, sabe-se que essa perspectiva se revela ainda distante, eis que exige mudanças a longo prazo.

Conforme entendimento de Azevedo (2015) as medidas adotadas pelos atores sociais em curto prazo dependem de ações concretas pautadas em uma consciência de todos considerando que a economia circular além de beneficiar o ambiente proporciona também redução do custo operacional e de produção, resultando em eficiência no uso de recursos e energia, e cabe ao Poder Público, enquanto responsável pelo cumprimento das regras e princípios instituídos pela Constituição da República e da legislação, tomar iniciativa para 
direcionar a concretização dos ideais de valores biológicos e técnicos frente à vida útil, seja de um produto ou serviço.

E para que a logística reversa auxilie na inserção dos princípios da economia circular faz-se necessário o incentivo do poder público nos ajustes interpretativos legais e nas pesquisas científicas, como também políticas públicas (GUARNIERI et al., 2020) para adequação do cenário brasileiro à transição e concretização prática, e que depende também, de incentivo aos cidadãos, para mudança de conduta relacionada ao descarte de resíduos sólidos.

Para Costa e Assahara, o papel do Estado é determinante, pois:

\begin{abstract}
Cabe ao Estado tributar a má utilização do meio ambiente, através de sanções administrativas, destinadas não apenas ao financiamento da disposição final dos resíduos, para eliminação ou reaproveitamento, mas para garantir a internalização dos gastos ambientais nos preços de bens e serviços públicos, tal como a promoção da saúde ambiental e humana a todos, assim como a adesão de tecnologia mais limpas. Entretanto observa-se que, mesmo as pessoas de direito público podem ser consideradas poluidoras, direta ou indiretamente, por atos omissos concernentes a sua administração (2020, p. 39-40).
\end{abstract}

Pode-se inserir a noção de justiça social em Nancy Fraser - o que, quem e como (para diálogo e executabilidade), ou seja, atores não estatais (amplo diálogo) e instituição formal (executabilidade a partir dos diálogos), uma relação bidimensional, com procedimentos justos e estrutura representativa (das presentes e futuras gerações de humanos e não humanos-garantir legitimidade democrática das suas deliberações) e exercício de seus representantes (garantir a obrigatoriedade de suas decisões de forma dialógica) (SILVA, FABRIZ, 2014, p. 126).

Demanda-se por uma governança dos fluxos materiais energéticos, ante a policrise global vivida; as teorias nacionais e internacionais trabalham para desenvolvimento de governança do sistema terrestre, e é preciso avançar no pensamento transdisciplinar para lidar com essas demandas, e a circularidade é essencial para que os objetivos previstos em lei sejam executados e auxiliem também o serviço público de limpeza.

\title{
CONSIDERAÇÕES FINAIS
}


O serviço público de limpeza vivencia uma crise de longa data, que se intensificou com o advento da pandemia de COVID-19, demandando maior atenção aos meios de contenção da contaminação.

A gestão integrada dos resíduos e a logística reversa necessitam de ações estatais assertivas, que incentivem a diminuição da geração de resíduos, e pautada em um diálogo entres as esferas do poder na busca de justa efetivação.

A economia circular é um instrumento que se alinha aos objetivos da Política Nacional de Resíduos Sólidos e pode contribuir para que o país possa fazer a transição para maior restauração dos sistemas naturais, mantendo os produtos e materiais em uso em seu mais alto nível ante ao ciclo reverso, retirando resíduos e poluição dede a fase inicial da cadeia.

As ações governamentais estratégicas são fundamentais para garantia da prestação do serviço público de limpeza. Para tanto, faz-se necessário aderir práticas auxiliares, como as sustentadas pela economia circular, e as políticas públicas são imprescindíveis para concretização prática.

\section{REFERÊNCIAS}

ABRELPE. Panorama dos Resíduos Sólidos no Brasil 2020. Disponível em: https://abrelpe.org.br/panorama-2020/. Acesso em: 03 ago. 2021.

ABRELPE. Panorama dos Resíduos Sólidos no Brasil 2018/2019. Disponível em: https://abrelpe.org.br/download-panorama-2018-2019/. Acesso em: 03 ago. 2021.

BANNWART JÚNIOR, Clodomiro José; SOUZA, Sharon Cristine Ferreira de. Política ambiental brasileira e sua regulação jurídica conforme os ditames da Ordem Econômica Constitucional. Revista de Direito da Cidade. vol. 5, no. 2, 2013, p. 258. Gale Academic OneFile. Disponível em:

https://link.gale.com/apps/doc/A372451031/AONE?u=capes\&sid=AONE\&xid=f7ab0e9d. Acesso em: 03 ago. 2021.

BRASIL. Constituição da República Federativa do Brasil. Constituição (1988). Brasília, DF, Senado, 5 de outubro de 1988. Disponível em: http://www.senado.gov.br/legislacao/const/con1988/CON1988_05.10.1988/CON1988.sht. Acesso em: 03 ago. 2021. 
BRASIL. 2010. Lei $n^{\circ}$ 12.305, de 02 de agosto de 2010. Institui a Política Nacional de Resíduos Sólidos e dá outras providências. Disponível em: http://www.planalto.gov.br/ccivil_03/_Ato2007-2010/2010/Lei/L12305.htm. Acesso em: 03 ago. 2021.

BRASIL. 2010. Decreto n. 7.404, de 23 de dezembro de 2010. Regulamenta a Lei no 12.305, de 2 de agosto de 2010, que institui a Política Nacional de Resíduos Sólidos, cria o Comitê Interministerial da Política Nacional de Resíduos Sólidos e o Comitê Orientador para a Implantação dos Sistemas de Logística Reversa, e dá outras providências. Disponível em: planalto.gov.br/ccivil_03/_ato2007-2010/2010/Decreto/D7404.htm. Acesso em: 03 ago. 2021.

BRASIL. Lei ${ }^{\circ}$. 8.080, de 19 de Setembro de 1990. Dispõe sobre as condições para a promoção, proteção e recuperação da saúde, a organização e o funcionamento dos serviços correspondentes e dá outras providências.

BRASIL. Lei no ${ }^{\circ} 10.257$ de 10 de Julho de 2001. Estatuto da Cidade. Regulamenta os arts. 182 e 183 da Constituição Federal, estabelece diretrizes gerais da política urbana e dá outras providências.

BRASIL. Lei $\mathrm{n}^{\mathrm{o}} .11 .445$ de 5 de Janeiro de 2007. Estabelece diretrizes nacionais para o saneamento básico; altera as Leis nos 6.766, de 19 de dezembro de 1979, 8.036, de 11 de maio de 1990, 8.666, de 21 de junho de 1993, 8.987, de 13 de fevereiro de 1995; revoga a Lei no 6.528 , de 11 de maio de 1978 ; e dá outras providências.

CEMPRE Review 2019. Um panorama da Reciclagem no Brasil. Disponível em: https://cempre.org.br/cempre-review/. Acesso em: 03 ago. 2021.

COSTA, Ilton Garcia da; ASSAHARA, Carolina Harumi. Descarte de Resíduos Agroindustriais como Atividade Potencialmente Poluidora: tutela ambiental e dano social. Revista Húmus. vol. 10, num. 30, 2020. Disponível em: http://www.periodicoseletronicos.ufma.br/index.php/revistahumus/article/view/14283/8199. Acesso em: 03 ago. 2021.

COSTA, Ilton Garcia da; CIRELLI, Gabriela Lopes. Resíduos sólidos nos municípios e sustentabilidade: a crise nos serviços públicos / Solid waste in municipalities and sustainability: crisis in public services. Revista de Direito da Cidade. v. 10, n. 3 (2018). Disponível em: https://www.e-publicacoes.uerj.br/index.php/rdc/article/view/32513. Acesso em: 03 ago. 2021.

COSTA, Ilton Garcia da; PIEROBON, Flavio; SOARES, Eliane C. A Efetivação do Direito ao Saneamento Básico no Brasil: Do Planasa ao Planasb. Revista Meritum - FUMEC, v. 13, n. 2, p. 335-358, 2018. Disponível em:

https://dialnet.unirioja.es/servlet/articulo?codigo=7871713. Acesso em: 03 ago. 2021. 
COSTA, Ilton Garcia da; TRANNIN, Alexandre Alberto; PINTO, Taís Caroline. A política pública de economia solidária como instrumento para contribuir com a inclusão social por meio do direito fundamental ao trabalho. In: COSTA, Ilton Garcia da; SANTIN, Valter Foleto (orgs.). Organizações sociais: efetivações e inclusão social. São Paulo: Verbatim, 2015.

CONFEDERAÇÃO Nacional da Indústria (CNI). 2018. Economia Circular: oportunidades e desafios para a indústria brasileira. Brasília: CNI. Disponível em:

https://www.portaldaindustria.com.br/publicacoes/2018/4/economia-circular-oportunidades-edesafios-para-industria-brasileira/\#circular-economy-opportunities-and-challenges-for-thebrazilian-industry. Acesso em: 03 ago. 2021.

DI PIETRO, Maria Sylvia Zanella. Direito Administrativo. 26ª ed., São Paulo: Atlas, 2013.

FERREIRA, Tatiane Cristovam; JOCA, Thais Arruda Costa; BROETTO, Fernando. Impactos Ambientais da Disposição dos Resíduos Sólidos Urbanos. In: Estudos sobre impactos ambientais: Uma abordagem contemporânea E82 Organizador: Alessandro Reinaldo Zabotto - Botucatu: FEPAF, 2019. Disponível em: fepaf.org.br/download/ImpactosAmbientais.pdf. Acesso em: 03 ago. 2021.

FOUNDATION, Ellen MacArthur. 2015. Rumo à Economia Circular: o racional de negócio para acelerar a transição. Disponível em:

https://www.ellenmacarthurfoundation.org/assets/downloads/Rumo-a\%CC\%80-economiacircular_Updated_08-12-15.pdf. Acesso em: 03 ago. 2021.

FOUNDATION, Ellen MacArthur; CEE100 Brasil. 2017. Uma Economia Circular no Brasil: uma abordagem exploratória inicial. Disponível em: https://www.ellenmacarthurfoundation.org/assets/downloads/Uma-Economia-Circular-noBrasil_Uma-Exploracao-Inicial.pdf. Acesso em: 03 ago. 2021.

GUARNIERI, P.; CERQUEIRA-STREIT, J. A.; BATISTA, L. C. 2020. Reverse logistics and the sectoral agreement of packaging industry in Brazil towards a transition to circular economy. Resources, Conservation and Recycling 153: 104541, 1-12.

ÍNDICE de Sustentabilidade de Limpeza Urbana (ISLU). 2020. Disponível em: https://selur.org.br/publicacoes/indice-de-sustentabilidade-da-limpeza-urbana-islu-edicao2020/. Acesso em: 03 ago. 2021.

LOUREIRO, Caio Marcio; SANTIN, Valter Foleto; LIMA, Thadeu Augimeri de Goes. Remanejamento Orçamentário Entre Elementos de Despesa Para Atendimento ao Mínimo Existencial em Época de Pandemia. Revista de Direito Sociais e Políticas Públicas. v. 6, n. 2, p. 19-39. Jul/dez 2020. Disponível em:

https://indexlaw.org/index.php/revistadspp/article/view/7071/pdf. Acesso em: 03 ago. 2021. 
OLIVEIRA, Paulo Augusto. O Estado regulador e garantidor em tempos de crise e o direito administrativo da regulação. Revista Digital de Direito Administrativo (RDDA),vol. 3, n. 1, 2016. Disponível em: http://www.revistas.usp.br/rdda/article/view/104322. Acesso em: 03 ago. 2021.

PHILIPPI JUNIOR, Arlindo. Ambiente, saúde \& sustentabilidade no contexto das cidades. Acta Paulista de Enfermagem. On-line version - ISSN 1982-0194. vol.30 no .3 São Paulo May/Jun. 2017. Disponível em:

https://www.scielo.br/scielo.php?script=sci_arttext\&pid=S0103-21002017000300001. Acesso em: 03 ago. 2021.

SANTIN, Valter Foleto. Serviço público e direitos humanos. Revista Paradigma. Ribeirão Preto-SP, a. XXIV, v. 28, n. 2, p. 134-153, mai./ago. 2019. Disponível em:

http://revistas.unaerp.br/paradigma/article/view/1332/1300. Acesso em: 03 ago. 2021.

SARLET, Ingo Wolfgang. A eficácia dos direitos fundamentais. $10^{\mathrm{a}}$ ed., Porto Alegre: Livraria do Advogado, 2010.

SILVA, Heleno Florindo; FABRIZ, Daury César. A noção de Justiça Social em Nancy Fraser e o Estado Plurinacional: da reificação cultural pela identidade nacional ao reconhecimento paritário do outro. Quaestio Iuris. vol.07, nº 01, Rio de Janeiro, 2014. pp 122-147.

Disponível em: https://www.e-

publicacoes.uerj.br/index.php/quaestioiuris/article/view/10796/0. Acesso em: 03 ago. 2021. 